\title{
Dinamik Model Epidemi SIRS dengan Laju Kematian Beragam
}

\author{
Ni’matur Rohmah, Wuryansari Muharini Kusumawinahyu \\ Jurusan Matematika, Fakultas MIPA, Universitas Brawijaya \\ Jl. Veteran Malang 65145 \\ Email: niks_rohmah91@yahoo.com,wmuharini@ub.ac.id
}

\begin{abstract}
ABSTRAK
Pada artikel ini dibahas model epidemi SIRS dengan laju kematian yang berbeda pada setiap subpopulasi. Di sini dilakukan analisis dinamik, yang meliputi analisis kestabilan lokal dan global pada titik kesetimbangan model. Kestabilan global ditentukan dengan memanfaatkan fungsi Lyapunov yang didefinisikan pada suatu domain di sekitar setiap titik kesetimbangan. Hasil analisis memperlihatkan terjadinya bifurkasi transkritikal dengan parameter bifurkasi berupa angka reproduksi dasar.
\end{abstract}

Kata kunci: model epidemi SIRS, laju kematian beragam, analisis kestabilan titik kesetimbangan, fungsi Lyapunov, angka reproduksi dasar, bifurkasi transkritikal.

\section{ABSTRACT}

This paper discusses a SIRS epidemic model with different mortality rate at every subpopulation. Dynamical analysis, such as local and global stabilities analysis on the equilibria, are performed. Global stability analysis is conducted by using Lyapunov functions which are defined at such a neighbourhood of equilibria. Analytical results show the appearance of transcritical bifurcation with basic reproduction number as a bifurcation parameter.

Keywords: SIRS epidemic model, different mortality rate, equilibria stability analysis, Lyapunov function, basic reproduction number, transcritical bifurcation.

\section{Pendahuluan}

Model epidemi SIRS (Susceptible-Infective-Recovered-Susceptible) merupakan model penyebaran penyakit yang membagi populasi menjadi tiga subpopulasi, yaitu subpopulasi individu rentan (Susceptible), subpopulasi individu terinfeksi (Invective), dan subpopulasi individu sembuh (Recovered). Model epidemi SIRS merupakan suatu pengembangan dari model klasik SIR yang telah dikemukakan oleh Hethcote [3] dan [4] pada tahun 1976 dan 1989. Model epidemi SIR mengasumsikan bahwa individu yang sembuh dari penyakit tidak akan terjangkit penyakit lagi, sedangkan model SIRS mewakili suatu situasi ketika individu yang pernah terinfeksi dan sembuh tidak memperoleh kekebalan terhadap penyakit, sehingga kembali menjadi individu yang rentan untuk terjangkit kembali. Analisis kestabilan lokal pada model epidemi SIRS telah dilakukan oleh De Le`on [2] pada tahun 2009. Pada model klasik SIR yang dikaji oleh Hethcote maupun pada model SIRS yang dikaji oleh De Le`on diasumsikan bahwa laju kematian di setiap subpopulasi seragam dan laju kematian total populasi sama dengan laju kelahirannya.

Selanjutnya, Adda dan Bichara [1] melakukan analisis kestabilan global pada model epidemi SIR dengan laju kematian beragam. Pada penelitiannya, Adda dan Bichara mengasumsikan bahwa laju kematian pada setiap subpopulasi, baik subpopulasi individu rentan, terinfeksi, maupun subpopulasi individu sembuh tidak sama. Selain itu, diasumsikan pula bahwa laju kelahiran total populasi sama dengan laju kelahirannya.

Pada artikel Adda dan Bichara [1] disarankan agar dilakukan pula analisis kestabilan global pada model epidemi SIRS dengan laju kematian beragam, agar dapat diamati pengaruh laju kematian yang beragam pada hasil analisis. Mengikuti saran tersebut, maka dalam artikel ini penulis menyajikan hasil analisis kestabilan lokal maupun global pada titik kesetimbangan model epidemi SIRS dengan laju kematian beragam. 


\section{Model Matematika}

Misalkan $s(t), i(t)$, dan $r(t)$ secara berturut-turut menyatakan kepadatan subpopulasi individu rentan, terinfeksi, dan sembuh. Model SIRS dengan laju kematian beragam yang dibahas pada tulisan ini digambarkan pada diagram kompartemen pada Gambar 1, yang menyatakan aliran individu antar subpopulasi. Individu pada kompartemen subpopulasi rentan akan menjadi individu terinfeksi bila terjangkit penyakit dan berpindah ke kompartemen subpopulasi terinfeksi. Selanjutnya, individu terinfeksi yang sembuh dari penyakit akan menjadi individu sembuh dan memasuki kompartemen subpopulasi sembuh. Pada model ini diasumsikan bahwa setiap bayi yang lahir dalam kondisi sehat sehingga masuk ke kompartemen subpopulasi sehat dan penyakit menular dengan laju penularan linear. Pada model kompartemen tersebut, $\Lambda$ menyatakan laju kelahiran, $\beta$ menyatakan koefisien laju penularan penyakit, $\gamma$ menyatakan laju kesembuhan individu terinfeksi, $\mu_{1}, \mu_{2}$, dan $\mu_{3}$ secara berturut-turut menyatakan laju kematian alami individu pada fase rentan, fase terinfeksi, dan fase sembuh. Parameter $\delta$ menyatakan laju kematian karena terinfeksi penyakit dan $v$ menyatakan laju penurunan kekebalan terhadap penyakit. Pada model ini diasumsikan bahwa kepadatan total populasi setiap saat konstan, yaitu sebesar $N=s(t)+i(t)+$ $r(t)$. Selain itu, diasumsikan pula bahwa laju kelahiran populasi sama dengan laju kematian populasi. Penjelasan lebih rinci mengenai formulasi model dapat dilihat pada Adda dan Bichara [1].

Berdasarkan Gambar 1 diperoleh sistem persamaan diferensial biasa dengan tiga variabel tak bebas yang secara berturut-turut menyatakan laju perubahan kepadatan subpopulasi rentan, subpopulasi terinfeksi, dan subpopulasi sembuh, yaitu

$$
\begin{aligned}
& \frac{d s}{d t}=\Lambda-\frac{\beta s i}{N}-\mu_{1} s+v r \\
& \frac{d i}{d t}=\frac{\beta s i}{N}-\left(\mu_{2}+\delta+\gamma\right) i \\
& \frac{d r}{d t}=\gamma i-\left(\mu_{3}+v\right) r .
\end{aligned}
$$

Karena $s+i+r=N$ dan laju kelahiran total populasi sama dengan laju kematiannya, maka $\Lambda=$ $\mu_{1} s+\left(\mu_{2}+\delta\right) i+\mu_{3} r$, sehingga sistem (1) menjadi

$$
\begin{aligned}
& \frac{d s}{d t}=-\frac{\beta s i}{N}+\left(\mu_{2}-\mu_{3}-v\right) i+\left(\mu_{3}+v\right) N-\left(\mu_{3}+v\right) s \\
& \frac{d i}{d t}=\frac{\beta s i}{N}-\left(\mu_{2}+\delta+\gamma\right) i \\
& \frac{d r}{d t}=\gamma i-\left(\mu_{3}+v\right) r .
\end{aligned}
$$

Perhatikan bahwa dua persamaan pertama pada sistem (2) tidak memuat variabel $r(t)$ sehingga untuk selanjutnya cukup dibahas sistem dengan dua persamaan pertama. Jika nilai $s(t)$ dan $i(t)$ telah diperoleh, maka nilai $r(t)$ nantinya dapat diperoleh dengan memanfaatkan hubungan $s+i+$ $r=N$. Jika $S=\frac{s}{N}$ dan $I=\frac{i}{N}$, maka sistem (2) dengan dua persamaan pertama dapat disederhanakan menjadi

$$
\begin{aligned}
& \frac{d S}{d t}=-\beta S I+\left(\mu_{2}-\mu_{3}-v\right) I-\left(\mu_{3}+v\right) S+\left(\mu_{3}+v\right) \\
& \frac{d I}{d t}=\beta S I-\left(\mu_{2}+\delta+\gamma\right) I .
\end{aligned}
$$




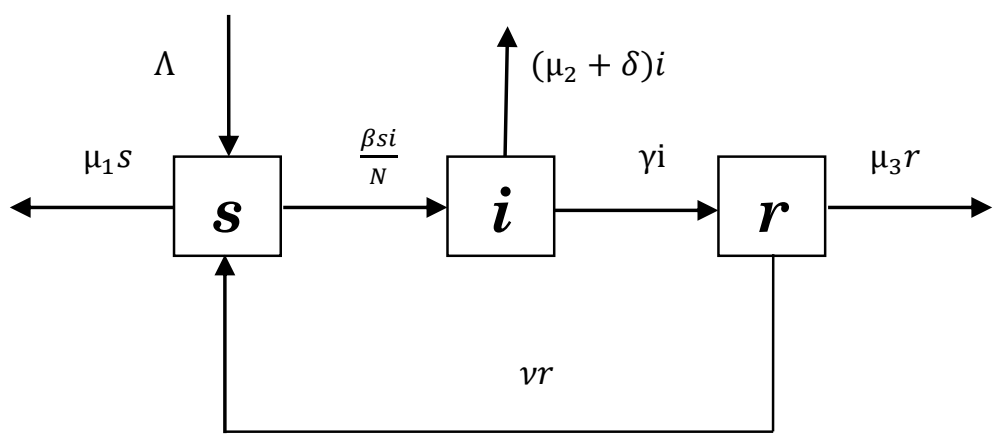

Gambar 1 Diagram kompartemen model epidemi SIRS dengan laju kematian beragam

\section{Hasil dan Pembahasan}

\subsection{Titik Kesetimbangan}

Kondisi setimbang tercapai ketika variabel yang semula berubah terhadap waktu menjadi konstan, yaitu kondisi ketika tak terjadi lagi perubahan nilai variabel pada model terhadap waktu. Dengan demikian, titik kesetimbangan diperoleh ketika $\frac{d S}{d t}$ dan $\frac{d I}{d t}$ pada persamaan (3) bernilai nol. Berdasarkan persamaan $\frac{d I}{d t}=0$ diperoleh dua kemungkinan, yaitu $I=0$ atau $S=\frac{\mu_{2}+\delta+\gamma}{\beta}$. Jika $I=0$ maka dari persamaan $\frac{d S}{d t}=0$ diperoleh $S=1$, sehingga diperoleh titik kesetimbangan pertama yang disebut sebagai titik kesetimbangan bebas penyakit $E_{0}=(1,0)$. Jika $S=\frac{\mu_{2}+\delta+\gamma}{\beta}$, diperoleh titik kesetimbangan ke dua, yaitu titik kesetimbangan endemi $E^{*}=\left(S^{*}, I^{*}\right)$, dengan $S^{*}=\frac{\mu_{2}+\delta+\gamma}{\beta}$ dan $I^{*}=$ $\frac{\mu_{3}+v}{\mu_{3}+v+\gamma}\left(1-\frac{1}{R_{0}}\right)$. Di sini $R_{0}=\frac{\beta}{\mu_{2}+\delta+\gamma}$ disebut sebagai angka reproduksi dasar. Perhatikan bahwa titik kesetimbangan endemi $E^{*}=\left(S^{*}, I^{*}\right)$ akan eksis hanya bila $R_{0}>1$. Jadi, bila $R_{0}<1$ maka hanya terdapat satu titik kesetimbangan yaitu titik kesetimbangan bebas penyakit, sedangkan bila $R_{0}>1$ maka terdapat dua titik kesetimbangan.

\subsection{Analisis Kestabilan Lokal}

Sifat kestabilan lokal kedua titik kesetimbangan tersebut ditentukan dengan melakukan linearisasi pada sistem persamaan (3) di sekitar titik kesetimbangan, sehingga diperoleh matriks Jacobi

$$
J(S, I)=\left(\begin{array}{cc}
-\beta I-\left(\mu_{3}+v\right) & -\beta S+\left(\mu_{2}+\delta-\mu_{3}-v\right) \\
\beta I & \beta S-\left(\mu_{2}+\delta+\gamma\right)
\end{array}\right) .
$$

Linearisasi sistem (3) di sekitar titik kesetimbangan $E_{0}=(1,0)$ memberikan matriks Jacobi

$$
J(1,0)=\left(\begin{array}{cc}
-\left(\mu_{3}+v\right) & -\beta+\left(\mu_{2}+\delta-\mu_{3}-v\right) \\
0 & \beta-\left(\mu_{2}+\delta+\gamma\right)
\end{array}\right),
$$

yang memiliki nilai eigen $\lambda_{1}=-\left(\mu_{3}+v\right)<0$ dan $\lambda_{2}=\left(R_{0}-1\right)\left(\mu_{2}+\delta+\gamma\right)$. Jika $R_{0}<1$ maka $\lambda_{2}<0$ sehingga titik kesetimbangan $E_{0}$ stabil asimtotik. Sebaliknya, jika $R_{0}>1$ maka titik kesetimbangan $E_{0}$ tak stabil pelana.

Selanjutnya, linearisasi di sekitar titik kesetimbangan endemi $E^{*}=\left(S^{*}, I^{*}\right)$ menghasilkan Matriks Jacobi 


$$
J\left(S^{*}, I^{*}\right)=\left(\begin{array}{cc}
-\left(\mu_{2}+\delta+\gamma\right) \frac{\mu_{3}+v}{\mu_{3}+v+\gamma}\left(R_{0}-1\right)-\left(\mu_{3}+v\right) & -\left(\gamma+\mu_{3}+v\right) \\
\left(\mu_{2}+\delta+\gamma\right) \frac{\mu_{3}+v}{\mu_{3}+v+\gamma}\left(R_{0}-1\right) & 0
\end{array}\right) .
$$

Perhatikan bahwa nilai trace $\left(J\left(E^{*}\right)\right)<0$ dan $\operatorname{det}\left(J\left(E^{*}\right)\right)>0$ sebab titik $E^{*}=\left(S^{*}, I^{*}\right)$ eksis hanya jika $R_{0}>1$. Berdasarkan sifat persamaan karakteristik matriks $J\left(E^{*}\right)$ yang dapat dikaitkan dengan nilai trace dan determinannya, diperoleh nilai eigen kompleks $\lambda_{1,2}=a+i b$, dengan $a<0$. Oleh karena itu, titik kesetimbangan $E^{*}$ stabil asimtotik.

\subsection{Analisis Kestabilan Global}

Selanjutnya, untuk menyelidiki sifat kestabilan global titik kesetimbangan $E_{0}=(1,0)$ digunakan fungsi Lyapunov seperti yang digunakan pada Adda dan Bichara [1], yaitu $L(S, I)=I$ pada domain $\Omega=\{(S, I) \mid S \geq 0, I \geq 0, S+I \leq 1\}$. Jelas bahwa $L\left(E_{0}\right)=0$ dan $L(S, I)>0, \forall(S, I) \neq(1,0)$. Kemudian, untuk memperlihatkan bahwa $L(S, I)$ merupakan fungsi Lyapunov kuat untuk $E_{0}$ harus dibuktikan bahwa $L^{\prime}(S, I)<0, \forall(S, I) \in \Omega \backslash\left(E_{0}\right)$. Perhatikan bahwa

$$
\begin{aligned}
L^{\prime}(S, I) & =I^{\prime}=\beta S I-\left(\mu_{2}+\delta+\gamma\right) I \\
& =\left(\mu_{2}+\delta \gamma\right) R_{0} S I-\left(\mu_{2}+\delta+\gamma\right) I \\
& =I\left(R_{0} S-1\right)\left(\mu_{2}+\delta+\gamma\right) .
\end{aligned}
$$

Jika $R_{0}<1$ maka $L^{\prime}(S, I)<0$, sehingga $L(S, I)$ merupakan fungsi Lyapunov kuat untuk $E_{0}$. Dengan demikian maka $E_{0}$ stabil asimtotik global jika $R_{0}<1$.

Untuk menyelidiki sifat kestabilan global titik kesetimbangan $E^{*}=\left(S^{*}, I^{*}\right)$ digunakan fungsi Lyapunov yang serupa dengan fungsi Lyapunov pada Adda dan Bichara, dengan melakukan sedikit modifikasi, yaitu menggantikan $\mu_{3}$ dengan $\mu_{3}+v$, yaitu

$$
L_{1}(S, I)=\left(S-S^{*}\right)-\frac{\mu_{3}+v+\gamma}{\beta} \ln \frac{\beta S-\mu_{2}-\delta+\mu_{3}+v}{\beta S^{*}-\mu_{2}-\delta+\mu_{3}+v}+\left(I-I^{*}\right)-I^{*} \ln \frac{I}{I^{*}},
$$

yang didefinisikan pada domain $\Omega_{0}=\left\{(S, I) \mid S>\frac{\mu_{2}+\delta-\mu_{3}-v}{\beta}, I \geq 0, S+I \leq 1\right\}$. Mudah dilihat bahwa $L_{1}\left(E^{*}\right)=0$. Dengan memanfaatkan kemonotonan fungsi $f(x)=x-\ln (x)$ dapat diperlihatkan bahwa $f(x) \geq 1$. Selanjutnya, secara berturut-turut dimisalkan $x=\frac{\beta S-\mu_{2}-\delta+\mu_{3}+v}{\beta S^{*}-\mu_{2}-\delta+\mu_{3}+v}$ dan $x=\frac{I}{I^{*}}$ untuk memperlihatkan bahwa suku ke dua dan ke tiga pada $L_{1}(S, I)$ positif. Dengan cara tersebut dapat dibuktikan bahwa $L_{1}(S, I)>0, \forall(S, I) \neq\left(S^{*}, I^{*}\right)$. Agar terbukti bahwa $L_{1}(S, I)$ merupakan fungsi Lyapunov kuat, maka harus diperlihatkan bahwa $L_{1}{ }^{\prime}(S, I)<0, \forall(S, I) \in \Omega_{0} \backslash\left(E^{*}\right)$. Dengan melakukan manipulasi aljabar dapat diperlihatkan bahwa

$$
\begin{aligned}
L_{1}{ }^{\prime}(S, I)= & \frac{d L_{1}}{d S} \cdot \frac{d S}{d t}+\frac{d L_{1}}{d I} \cdot \frac{d I}{d t} \\
= & \frac{d S}{d t}-\left(\mu_{3}+v+\gamma\right) \frac{\left(\mu_{3}+v\right)+\left(\mu_{2}+\delta-\mu_{3}-v\right) I-\left(\mu_{3}+v\right) S-\beta S I}{\beta S-\mu_{2}-\delta+\mu_{3}+v}+\beta S I-\left(\mu_{2}+\delta+\gamma\right) I \\
& \quad-I^{*}\left(\beta S-\left(\mu_{2}+\delta+\gamma\right)\right) \\
= & \dot{S}-\left(\mu_{3}+v+\gamma\right) \frac{\left(\mu_{3}+v\right)-\left(\mu_{3}+v\right) S}{\beta S-\mu_{2}-\delta+\mu_{3}+v}-\left(\mu_{3}+v+\gamma\right) \frac{\left(\mu_{2}+\delta-\mu_{3}-v-\beta S\right) I}{\beta S-\mu_{2}-\delta+\mu_{3}+v} \\
& \quad+\left(\beta S-\left(\mu_{2}+\delta+\gamma\right)\right) I-I^{*}\left(\beta S-\left(\mu_{2}+\delta+\gamma\right)\right)
\end{aligned}
$$




$$
\begin{aligned}
& =\left(\mu_{3}+v\right)-\left(\mu_{3}+v\right) S-\left(\mu_{3}+v+\gamma\right) \frac{\left(\mu_{3}+v\right)-\left(\mu_{3}+v\right) S}{\beta S-\mu_{2}-\delta+\mu_{3}+v}-I^{*}\left(\beta S-\left(\mu_{2}+\delta+\gamma\right)\right) \\
& =\left(\mu_{3}+v\right)(1-S)-\left(\mu_{3}+v+\gamma\right) \frac{\left(\mu_{3}+v-\mu_{3} S-v S\right)}{\beta S-\mu_{2}-\delta+\mu_{3}+v}-I^{*}\left(\beta S-\left(\mu_{2}+\delta+\gamma\right)\right) \\
& =\left(\mu_{3}+v\right)(1-S)\left(1-\frac{\mu_{3}+v+\gamma}{\beta S-\mu_{2}-\delta+\mu_{3}+v}\right)-I^{*}\left(\beta S-\left(\mu_{2}+\delta+\gamma\right)\right) \\
& =\left(\mu_{3}+v\right)(1-S)\left(1-\frac{\mu_{3}+v+\gamma}{\beta S-\mu_{2}-\delta+\mu_{3}+v}\right)-\frac{\mu_{3}+v}{\left(\mu_{3}+v+\gamma\right)\left(1-S^{*}\right)\left(\beta S-\left(\mu_{2}+\delta+\gamma\right)\right)} \\
& =\left(\mu_{3}+v\right)(1-S)\left(1-\frac{\mu_{3}+v+\gamma}{\beta S-\mu_{2}-\delta+\mu_{3}+v}\right)-\frac{\mu_{3}+v}{\mu_{3}+v+\gamma}\left(1-S^{*}\right)\left(\beta S-\beta S^{*}\right) \\
& =\left(\mu_{3}+v\right)(1-S)\left(\frac{-\mu_{2}-\delta+\mu_{3}+v+\beta S-\mu_{3}-v-\gamma}{-\mu_{2}-\delta+\mu_{3}+v+\beta S}\right)-\frac{\mu_{3}+v}{\left(\mu_{3}+v+\gamma\right)\left(1-S^{*}\right)\left(\beta S-\beta S^{*}\right)} \\
& =\left(\mu_{3}+v\right)(1-S)\left(\frac{\beta S-\beta S^{*}}{\beta S-\mu_{2}-\delta+\mu_{3}+v}\right)-\frac{\mu_{3}+v}{\mu_{3}+v+\gamma}\left(1-S^{*}\right)\left(\beta S-\beta S^{*}\right) \\
& =-\left(\mu_{3}+v\right) \beta\left(S^{*}-S\right)\left(\frac{(1-S)}{\beta S-\mu_{2}-\delta+\mu_{3}+v}-\frac{\left(1-S^{*}\right)}{\mu_{3}+v+\gamma}\right) \\
& =-\left(\mu_{3}+v\right) \beta\left(S^{*}-S\right)\left(\frac{(1-S)}{\beta S-\mu_{2}-\delta+\mu_{3}+v}-\frac{\left(1-S^{*}\right)}{\beta S^{*}-\mu_{2}-\delta+\mu_{3}+v}\right) \\
& =-\left(\mu_{3}+v\right) \beta\left(S^{*}-S\right)\left(\frac{\left(\beta S^{*}-\mu_{2}-\delta+\mu_{3}+v\right)(1-S)-\left(1-S^{*}\right)\left(\beta S-\mu_{2}-\delta+\mu_{3}+v\right)}{\left(\beta S-\mu_{2}-\delta+\mu_{3}+v\right)\left(\beta S^{*}-\mu_{2}-\delta+\mu_{3}+v\right)}\right) \\
& =-\left(\mu_{3}+v\right) \beta\left(S^{*}-S\right)\left(\frac{\beta\left(S^{*}-S\right)+\left(-\mu_{2}-\delta+\mu_{3}+v\right)\left(S^{*}-S\right)}{\left(\beta S-\mu_{2}-\delta+\mu_{3}+v\right)\left(\beta S^{*}-\mu_{2}-\delta+\mu_{3}+v\right)}\right) \\
& =-\left(\mu_{3}+v\right) \beta\left(S^{*}-S\right)\left(\frac{\left(S^{*}-S\right)\left(\beta-\mu_{2}-\delta+\mu_{3}+v\right)}{\left(\beta S-\mu_{2}-\delta+\mu_{3}+v\right)\left(\mu_{3}+v+\gamma\right)}\right) \\
& =\frac{-\left(\mu_{3}+v\right) \beta}{\mu_{3}+v+\gamma}\left(\frac{\beta-\mu_{2}-\delta+\mu_{3}+v}{\beta S-\mu_{2}-\delta+\mu_{3}+v}\right)\left(S^{*}-S\right)^{2} .
\end{aligned}
$$

Agar $L_{1}{ }^{\prime}(S, I)<0$, maka

$$
\frac{\beta-\mu_{2}-\delta+\mu_{3}+v}{\beta S-\mu_{2}-\delta+\mu_{3}+v}
$$

harus bernilai positif. Karena $(S, I) \in \Omega_{0}$ maka $\beta S-\mu_{2}-\delta+\mu_{3}+v>0$. Selain itu, telah diperlihatkan bahwa titik kesetimbangan endemi $E^{*}=\left(S^{*}, I^{*}\right)$ eksis jika $R_{0}=\frac{\beta}{\mu_{2}+\delta+\gamma}>1$. Dengan perkataan lain $\beta-\mu_{2}-\delta>\gamma$. Akibatnya, $\beta-\mu_{2}-\delta+\mu_{3}+v>\gamma+\mu_{3}+v>0$. Dengan demikian $\frac{\beta-\mu_{2}-\delta+\mu_{3}+v}{\beta S-\mu_{2}-\delta+\mu_{3}+v}>0$. Jadi telah diperlihatkan bahwa $L_{1}(S, I)$ memenuhi syarat sebagai fungsi Lyapunov kuat. Dengan demikian dapat disimpulkan bahwa $E^{*}$ eksis dan bersifat stabil asimtotik global jika $R_{0}>1$.

Hasil analisis kestabilan tersebut dapat dirangkum sebagai berikut. Jika $R_{0}<1$ hanya terdapat titik kesetimbangan bebas penyakit $E_{0}=(1,0)$ dan bersifat stabil asimtotik. Jika $R_{0}>1$ titik kesetimbangan bebas penyakit $E_{0}=(1,0)$ berubah sifat menjadi tak stabil pelana dan diperoleh titik kesetimbangan baru, yaitu titik kesetimbangan endemi $E^{*}=\left(S^{*}, I^{*}\right)$ yang bersifat stabil asimtotik. Fenomena ini mengindikasikan terjadinya bifurkasi transkritikal pada sistem (3) dengan parameter bifurkasi $R_{0}$ dan nilai bifurkasi $R_{0}=1$. Bifurkasi semacam ini pada umumnya selalu dijumpai pada model-model penyebaran penyakit, seperti yang diperlihatkan pula pada model SIRS dengan laju kematian seragam yang dikaji oleh De Le`on [2]. Selain itu, nilai titik kesetimbangan Endemi juga sangat dipengaruhi oleh laju kematian subpopulasi terinfeksi. Dapat diartikan bahwa jika terjadi wabah maka kepadatan subpopulasi rentan akan tinggi dan kepadatan subpopulasi terinfeksi akan rendah ketika parameter laju kematian subpopulasi terinfeksi $v$ besar. 
Nilai $R_{0}$ yang diperoleh dari hasil analisis pada model SIRS dengan laju kematian beragam hampir sama dengan nilai $R_{0}$ yang diperoleh dari model dengan laju kematian seragam pada De Le`on [2]. Namun, pada De Le`on [2] tidak terlihat secara jelas, laju kematian subpopulasi mana yang berpengaruh terhadap angka reproduksi dasar, di antara tiga laju kematian yang terdapat pada model. Tidak seperti pada De Le'on [2], pada model SIRS dengan laju kematian beragam terlihat bahwa ternyata laju kematian alami subpopulasi individu terinfeksilah yang berpengaruh pada angka reproduksi dasar secara berbanding terbalik. Bila laju kematian ini besar maka $R_{0}$ mengecil menjadi kurang dari 1 , sehingga tidak terjadi wabah sebab titik kesetimbangan endemi $E^{*}=\left(S^{*}, I^{*}\right)$ tidak eksis dan titik kesetimbangan bebas penyakit stabil. Hal ini dapat diartikan sebagai berkurangnya peluang untuk terjadinya penyebaran penyakit karena bertambahnya individu terinfeksi yang mati secara alami.

\subsection{Simulasi Numerik}

Simulasi numerik dilakukan untuk mengilustrasikan hasil analisis yang telah dilakukan. Oleh karena itu, simulasi dilakukan pada dua kasus, yaitu kasus $R_{0}<1$ dan $R_{0}>1$. Pada kasus pertama digunakan nilai-nilai parameter $\beta=5, \gamma=2, \mu_{2}=7, \mu_{3}=6, \delta=3$ dan $v=8$ sehingga diperoleh $R_{0}=$ $0.41667<1$. Untuk kasus $R_{0}<1$ digunakan nilai-nilai parameter $\beta=10, \gamma=2, \mu_{2}=2, \delta=3, \mu_{3}=3$, dan $v=6$ sehingga diperoleh $R_{0}=1.42857>1$. Hasil simulasi disajikan sebagai potret fase di ruang tiga dimensi $(S, I, R)$. Nilai $R(t)$ diperoleh dari hubungan $S(t)+I(t)+R(t)=1$, sehingga titik kesetimbanganpun dapat disajikan dalam koordinat tiga dimensi $(S, I, R)$.

Pada kasus pertama ingin diperlihatkan bahwa titik kesetimbangan $E_{0}=(1,0,0)$ stabil asimtotik global. Oleh karena itu diambil beberapa nilai awal yang jauh dari $E_{0}$ yaitu $(0.5,0.25,0.25),(0.3,0.3,0.4)$, dan $(0.1,0.6,0.3)$. Hasil simulasi dapat dilihat pada Gambar 2, yang memperlihatkan bahwa orbitorbit solusi yang berawal di tiga posisi tersebut menuju titik kesetimbangan yang sama yaitu $E_{0}=$ $(1,0,0)$.

Pada kasus ke dua diperlihatkan bahwa kedua titik kesetimbangan eksis, titik kesetimbangan bebas penyakit $E_{0}=(1,0,0)$ tak stabil pelana, sedangkan titik kesetimbangan endemi stabil asimtotik global. Dengan menggunakan parameter tersebut, diperoleh titik kesetimbangan endemi $E^{*}=$ $\left(S^{*}, I^{*}, R^{*}\right)=(0.7,0.245,0.055)$. Untuk memperlihatkan sifat kestabilan kedua titik kesetimbangan tersebut, diambil nilai awal yang jauh dari $E^{*}$ dan nilai awal yang dekat dengan $E_{0}$, yaitu $(0.3,0.3,0.4),(0.5,0.2,0.3)$, dan $(0.8,0.1,0.1)$. Pada Gambar 3 diperlihatkan hasil simulasi yang menunjukkan bahwa orbit-orbit solusi yang berawal di tiga posisi tersebut meninggalkan titik $E_{0}=$ $(1,0,0)$ dan pada akhirnya menuju titik kesetimbangan yang sama yaitu $E^{*}=(0.7,0.245,0.055)$.

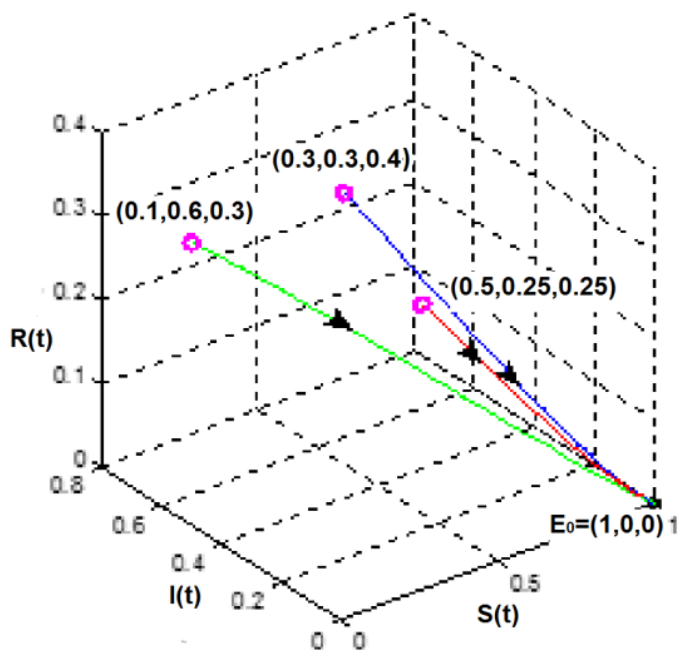

Gambar 2. Potret fase untuk $R_{0} \leq 1$

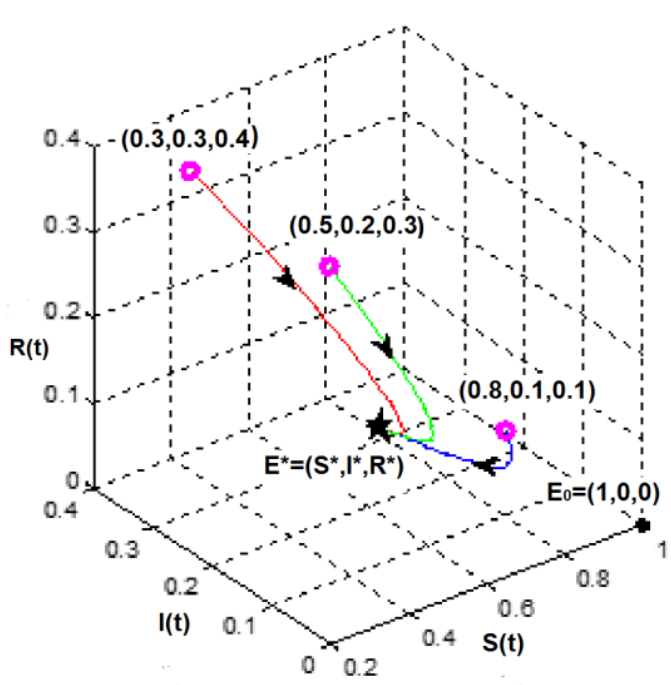

Gambar 3. Potret fase untuk $R_{0}>1$ 


\section{Kesimpulan}

Dari model epidemi SIRS dengan tingkat kematian beragam diperoleh dua titik kesetimbangan, yaitu kesetimbangan bebas penyakit dan endemik. Eksistensi titik kesetimbangan endemi ditentukan oleh angka reproduksi dasar yang dipengaruhi oleh laju kematian individu terinfeksi. Jika angka reproduksi dasar kurang dari 1, maka hanya terdapat titik kesetimbangan bebas penyakit yang bersifat stabil asimtotik global. Selanjutnya, jika angka reproduksi dasar meningkat melampaui nilai 1, maka titik kesetimbangan bebas penyakit berubah menjadi tak stabil pelana dan muncul titik kesetimbangan endemi yang bersifat stabil asimtotik global. Dengan demikian pada model SIRS dengan laju kematian beragam terjadi bifurkasi transkritikal dengan angka reproduksi dasar sebagai parameter bifurkasi. Selain itu, hasil simulasi numerik yang dilakukan mendukung hasil analisis yang telah diperoleh.

\section{Daftar Pustaka}

1. Adda, P. dan Bichara, D., 2012, Global Stability for SIR and SIRS Models with Differential Mortality, International Journal of Pure and Applied Mathematics, 80 (3): 425 - 433.

2. De Le`on, C. V., 2009, Constructions of Lyapunov Functions for Classic SIS, SIR, and SIRS Epidemic Models with Variable Population Size, Foro-Red-Mat: Revista Electronica de Contenido.

3. Hethcote, W. H., 1976, Qualitative Analyses of Communicable Disease Models, Math. Bioscience, 28: $335-356$.

4. Hethcote, W. H., 1989, Three Basic Epidemiological Models, Applied Mathematical Ecology, 18: $119-144$ 
Rohmah \& Kusumawinahyu / JMI Vol 10 No 1, April 2014, hal 1-7 